\title{
Pipeline walls hydrophobic properties study and their protective coatings used in trenchless technologies
}

\author{
Vladimir Orlov $^{1, *}$ \\ ${ }^{1}$ Moscow State University of Civil Engineering (National Research University), Department of Water \\ Supply and Water Disposal, Yaroslavskoye sh. 26, 129337 Moscow, Russia
}

\begin{abstract}
The results of field and theoretical studies to determine the degree of hydrophobicity of the inner pipe walls in static and dynamic conditions are reported. The water drops spreading nature in contact with the horizontal and concave surface of different materials with the definition of contact angles is determined. The flow pattern formed when the critical mass of liquid miniflow is reached on an inclined surface in the form of an open trough was studied. The geometric parameters of the frontal and coaxial miniflow projections were determined, its dimensions and hydraulic characteristics were studied. The trial stand design for the protective coatings hydrophobic properties study was presented and described and method of evaluation of the pipeline work surfaces hydrophobic properties by applying the relative hydrophobicity ratio. Calculation formulas of the relative hydrophobicity ratio for work surfaces were presented. The relationships of hydrophobicity of various coatings used in the trenchless technologies to relative roughness coefficients were established.
\end{abstract}

\section{Introduction}

Nowadays trenchless technologies are widely used for rapid recovery of old water supply and water disposal pipelines [1]. Recovered pipelines must have the appropriate strength parameters determined by static calculations, and ensure a long efficient lifetime [2]. No deterioration of hydraulic parameters compared to the initial for corresponding piping material shall be observed in the recovered pipelines [3]. In addition to the strength and hydraulic parameters the evaluation of such indicators as energy saving, which are derived from hydraulic, can be made. Mechanical parameters - the degree of abrasion of inner pipes surfaces and their coatings, fatigue wear, etc. are subject to accounting [4]. Such parameters as hydrophobicity and hydrophilicity stand apart in the drinking and waste water transportation, and more precisely in the physical and chemical properties study of the inner pipe walls or their protective coatings.

The main objective of ongoing research studies was to examine the liquid contact with the work surfaces and determine the surfaces topology (roughness) impact on the liquid

* Corresponding author: voda@mgsu.ru 
flow dynamics. Such works were mainly carried out for thin (mini) channels with ultra hydrophobic surfaces study [5].

Work surfaces hydrophobicity in contact with liquid environments can be encountered in various fields of engineering [6]. Pipes and their protective coatings, where there is a need for the reduction of hydraulic resistance for the energy saving are no exception [7].

The degree of hydrophobicity is evaluated in static conditions by measuring the contact angle of liquid drop applied on the surface of the material to be tested [8]. By contact angle is meant the angle between the tangent to the droplet surface and wetted surface, where the angle vertex lies at the wetting line. With significant quantities of contact angle $\left(90^{\circ}\right.$ and above) the surface is considered as superhydrophobic [9].

The researchers have established a classification of surfaces, depending on their degree of hydrophobicity [9]. For many years, the following issues are studied: drops slip from surfaces with different roughness [10], hydrodynamic interaction of flows with superhydrophobic surfaces [11], liquid contact angle measurement with the surface under flow conditions [12], laser research of the superhydrophobic surfaces structure [13], nature of the change in the contact angle during the drop movement on different surfaces $[14,15]$ measurement of viscous droplets speed moving down on inclined surface [16], use of atomic force microscopy to measure the boundary sliding on hydrophilic, hydrophobic and superhydrophobic surfaces [17] spreading and slipping of liquid droplets on solid surfaces [18] and others. For example, in the article [19] in the observation period of water droplets during its movement the contact angles to the hydrophobic surface normal depending on the magnitude of velocity were investigated. With rapid sliding down the superhydrophobic surface the contact angle was $150^{\circ}$, whereas at the slower sliding and rolling the contact angle to the surface normal ranged from 100 to $79.5^{\circ}$. At the same time it was noted that the drop maintained its shape during movement. This was corroborated by the equality of distances traveled by the advancing and retreating drop edge.

According to the experiments results [20] the drop slides down the superhydrophobic surface without rolling. Some researchers have studied the drops movement and their spreading on the solid surface in terms of three-phase contact [21]. The drops falling and spreading model was proposed to identify conditions when the drop has a long tail.

In this paper some other aspects of fluid-surface interaction were raised:

- water drops behavior (not more than $0.55 \mathrm{ml}$ ) in static on different work surfaces in contact with the horizontal and concave surfaces structure;

- behavior of the moving liquid flow layer, i.e. in dynamics, down the inclined surface in the form of a trough, simulating the pipeline with applied repair materials which are used in the water supply and water disposal networks renovation by trenchless technologies [1].

Taking into consideration the well-known basic provisions on the static and dynamic wettability studies [22], the aim of our studies was to determine the most effective protective coating of pipelines identifying the linkages between its degree of hydrophobicity and hydraulic parameters [23].

\section{Experiments}

\subsection{Materials and research methods}

The following equipment was used as photo and motion-picture cameras for drops and liquid miniflow configuration: digital reflex camera Sony 550, lens DT 1.8/50 SAM with Kenko Extension Tube Set DG in the continuous multi-frame shooting mode and digital video camera Sony HDR-CX250E. Drinking water was used as liquid for drops formation and its miniflow for simulating the water supply system pipeline operation. 
Static studies were made on the most common materials of pipe protective coatings: polypropylene, polymer sleeve by "Per Aarsleff" (Denmark) and "Wawin" (Holland), thin protective film of "3M" (USA) etc. In addition, Smart Surface coating was subject to the study regarding the hydrophobicity, developed by FUJIFILM HUNT (Belgium).

Dynamic studies were carried out on the stand with though length of $1 \mathrm{~m}$, which simplified diagram is shown in Fig. 1. Formation and spontaneous liquid flow movement in the trough was ensured by its slope and liquid critical mass volume.

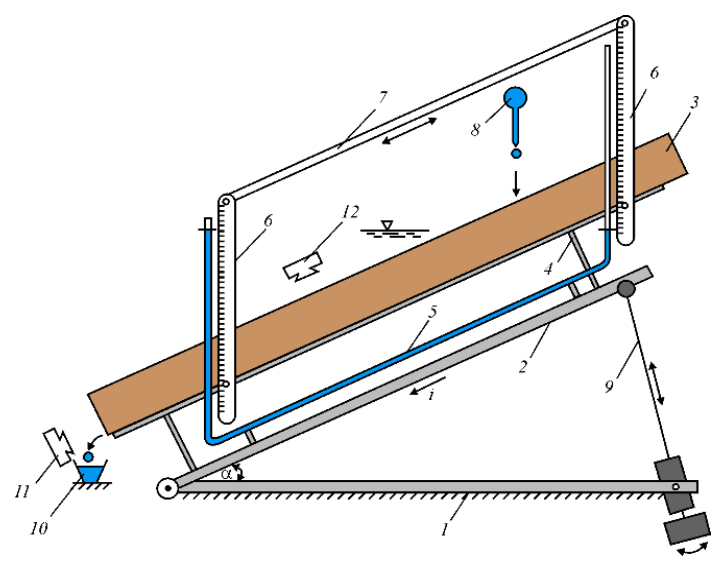

Fig. 1. Layout view of the experimental installation with maximum trough slope of $1 \mathrm{~m}$ long 1 - support frame; 2 - rack; 3 - open trough (tray); 4 - stands; 5 - system of communicating vessels; 6 - measuring rules; 7 - control rail; 8 - pipette with water; 9 - mechanical jack rod; 10 - drops collector; 11,12 - front and coaxial flow cameras, respectively.

\subsection{Research methodology}

\subsubsection{Static studies}

During experiments, the contact angles were calculated by determining the derivative of the function describing the front projection of a drop on the work surface, and checked with photographing results. Experiments show that the drops nature for hydrophilic materials is similar in configuration to the inverted parabola, and for hydrophobic to semicircle.

The parabola equation is described by the Lagrange polynomial (1):

$$
y=4 h x(a-x) / a^{2} \text { or } y=-4 h\left(x^{2}-a x\right) / a^{2},
$$

where $h$ - parabola height (distance from the horizontal plane to the vertex); $a$ - drop diameter spread out on the horizontal plane.

Values $a$ and $h$ were determined geometrically from the drops front projection photos on the protective coatings. By substituting the values $a$ and $h$ in the formula (1), it takes a particular form, reflecting the front surface nature of spreading drop as a parabola.

Methods of determining the contact angle $\alpha$ for a drop in the form of an inverted parabola is as follows. The coordinate axis with the center in the leftmost its part are imposed on the frontal drop projection. Point coordinates (rightmost) are marked on the abscissa axis through which the tangent passes to the curve described by the parabola equation, for example, $y=-0.050416 x^{2}+0.731 x$ (Fig. 2). Then derivative of this function is taken, which for this case is written as $y^{\prime}=-0.050416 \cdot 2 x+0.731$ or $y^{\prime}=-0.100832 x+0.731$. The figure 0.731 characterizes a slope of the tangent to the parabola in the rightmost point $C$ with coordinates $(14.5 ; 0)$ or slope $\alpha$ of the tangent at this point. Fig. 1 shows that the 
tangent slope $\alpha$ is approximately $36^{\circ}$. Thus, the contact angle for the analyzed work surface (polypropylene) is significantly less than $90^{\circ}$, indicating a low degree of material hydrophobicity. On other surfaces mentioned above the contact angles were $45-60^{\circ}$.
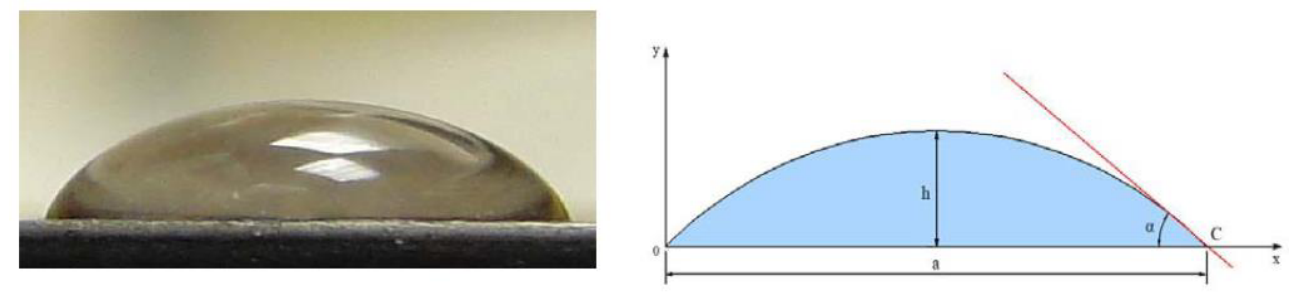

Fig. 2. The drop photo on the horizontal hydrophilic polypropylene surface and the image of its front projection with the contact angle of $36^{\circ}$.

In turn, the circle equation as a complex function can be written in the standard form:

$$
y^{2}+x^{2}=r^{2}
$$

where $\mathrm{r}$ - radius of circle formed by the boundary of drop front projection.

Methods of determining the contact angle at the drop spreading in the form of semicircle is mostly the same as the above-described algorithm for the parabola. Here, the function differentiation through the auxiliary variable is made. In the final form, for example, in the differentiation of composite function $y=\sqrt{r^{2}-x^{2}}$, its derivative is expressed in the form:

$$
y^{\prime}=\frac{-x}{\sqrt{r^{2}-x^{2}}}
$$

By substituting in the formula (3) of averaged circle radius $r$ and $x$ value corresponding to the right extreme circle point lying on the horizontal axis the numerical value of the derivative is determined. The absolute value of the obtained derivative is the tangent slope to the circle at the rightmost point or slope $\operatorname{tg} \alpha$ to the tangent at this point. Fig. 3 shows the photo and layout view of frontal drop surface in the form close to semicircle on the curved surface of the Smart Surface coating, which falls in the category of hydrophobic.

It must be noted that Fig. 3 shows the ordinate axis passing through the circle center, the abscissa axis coinciding with the horizontal plane, and $O E=a / 2$ value is equal to 26.97 , i.e. point coordinates where the tangent passing to the semicircle are $(26.97 ; 0)$. The circle radius value expressed as $r=A O+O B$ is 27 (dimension is not indicated due to the multiple photo and drawing zooming). Visual analysis in Fig. 3 and location of the tangent in point $E$ indicates that it passes at an angle of more than $90^{\circ}$. The derivative is defined as the tangent of adjacent angle $\beta$.

$$
y^{\prime}=\operatorname{tg} \beta=\left|\frac{-26.97}{\sqrt{27^{2}-26.97^{2}}}\right|=|-21.119|
$$

At the tangent value of 21.119 angle $\beta$ is about $87^{\circ}$, and the contact angle is determined as the difference: $\alpha=180^{\circ}-87^{\circ}=93^{\circ}$. The obtained values of contact angle indicate a high degree of hydrophobicity of the Smart Surface coating material. This assumes its widespread use as an alternative to other protective pipeline coatings with the lower degree of hydrophobicity. 

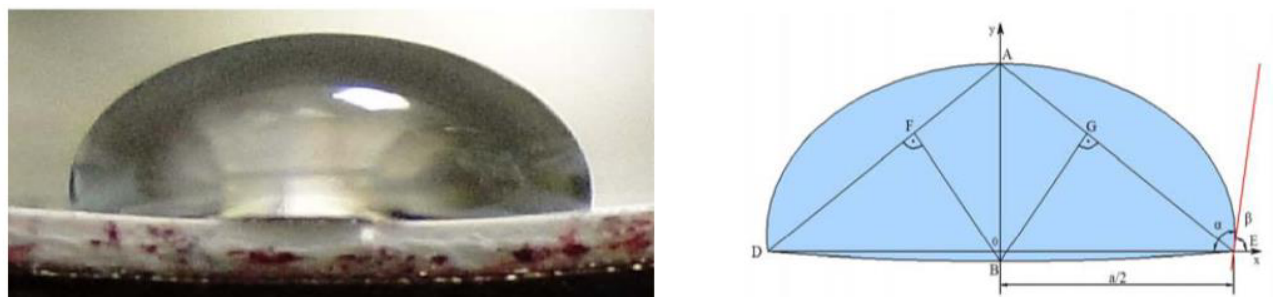

Fig. 3. The drop photo on the concave surface of the Smart Surface hydrophobic material and the image of its front projection with the contact angle of $93^{\circ}$.

\subsubsection{Dynamic studies}

General view of the miniflow at a certain work surface slope $i$ (see Fig. 1) is shown in Fig. 4. The head and tail miniflow regions are presented in the form of volumetric structure (half of the spherical segment), $A B C D A$ and $A^{\prime} B^{\prime} C^{\prime} D^{\prime} A$ ', respectively. Their projection on a vertical plane can be displayed in the form of a lens (circumference portion) by analogy with the frontal drop projections. The experiments consisted in the frontal and coaxial photos and filming, and miniflow dimensions determination, mathematical description of shapes and elements of miniflow, by which the degree of material hydrophobicity can be evaluated and identify, where possible, its relation with geometric miniflow dimensions.

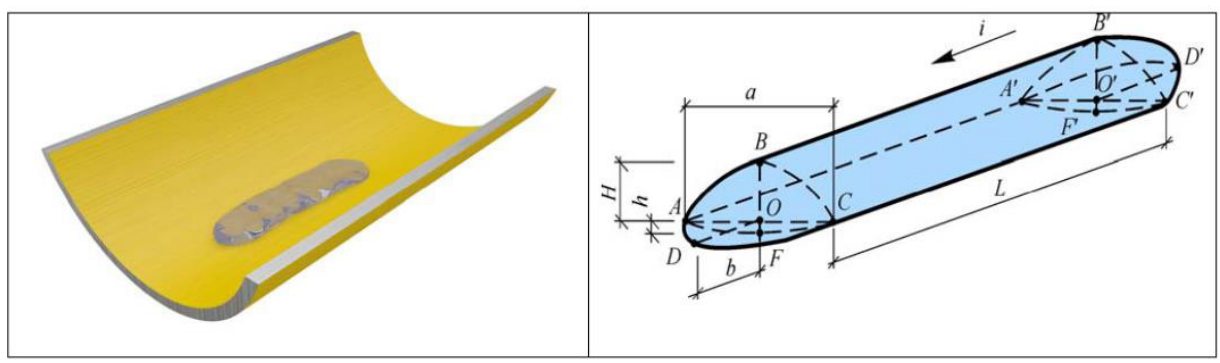

Fig. 4. Axonometric miniflow diagram formed as a result of the critical liquid volume flow on the inclined trough in the form of a tray of $1 \mathrm{~m}$ long $a, L$ - average values of width and length of the compact miniflow region, respectively; $H, h$ - height of the upper and lower lenses, respectively; $b-$ height of the half of spherical segment of the miniflow head region; $A F C, A A^{~} C^{\prime} C$ - wetted perimeter and surface of the compact miniflow region $\left(S_{w e t}\right)$, respectively; $i$ - trough slope.

\section{Results and discussion}

Fragments of the frontal and coaxial miniflow filming on polypropylene troughs and "3M" protective coating are shown in Fig. 5.

Photographs analysis in Fig. 5 shows that both in static and in dynamic the tendency of different degrees of hydrophobicity in the different materials is observed. Based on the obtained data it was suggested to evaluate the degree of hydrophobicity in dynamic both by the contact angle and by relative hydrophobicity ratio determination $K_{\text {rell }}$ :

$$
K_{\text {rel }}=S_{\text {up }} /\left(S_{\text {wet. }} \cdot i\right),
$$

where $S_{u p}$ - upper lens area $(A B C O A), \mathrm{mm}^{2} ; S_{\text {wet. }}$ - trough surface wetting area $\left(A A^{\circ} C^{\prime} C\right)$ by compact miniflow part $L, \mathrm{~mm}^{2} ; i$ - trough slope. 


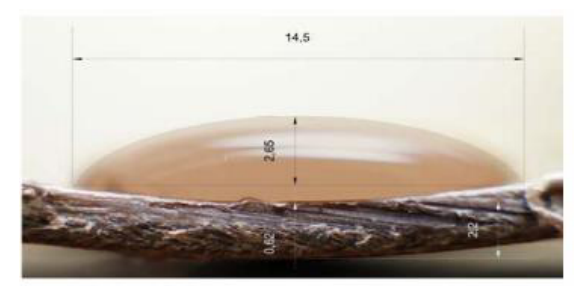

photo No. 2988

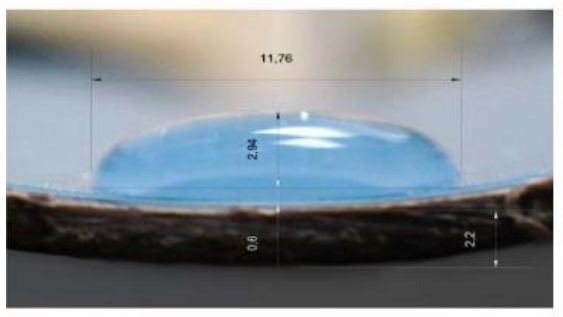

photo No. 3185

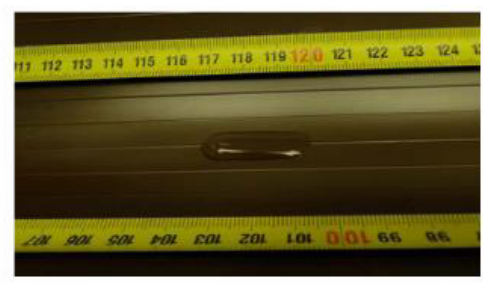

polypropylene trough

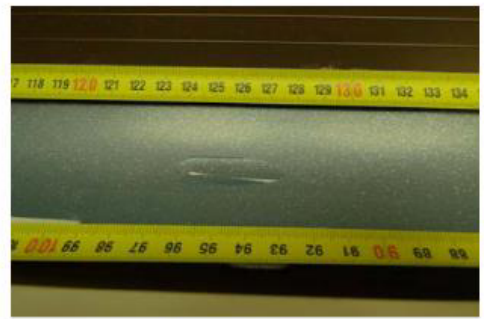

trough with "3M" coating

Fig. 5. Selected fragments of the frontal and coaxial photos.

In the course of dynamic field studies of degree of hydrophobicity of the Smart Surface coating (byprocessing of frontal and coaxial photographic materials and filming) the dependence of the flow width and the height of upper lens $H$ and lower lens $h$ on the miniflow $N$ mass in wide ranges of the trough slope $i$ from 0.01 to 0.11 was identified (within the boundaries of optimal pipelines gradient under pressureless mode of operation). Based on the diagrams in Fig. 6, obtained curves are described by linear functions.

With regards to the modification of such geometrical parameters as the average flow width $a$ and height $h$ of the lower lens in the analyzed mass range $N$ it could be stated that these values remain practically unchanged, and compensation for the increase of liquid mass $N$ entering the trough affects the length $L$ of the compact miniflow region towards its increase.

Conclusions from the analysis of dependencies $a=f(N), H=f(N)$ and $h=f(N)$ may be the fact that the experiments for the determination of degree of hydrophobicity of the analyzed materials on the stand can be carried out at any trough slope with the possibility of forming relatively stable length $\mathrm{L}$ of compact miniflow region and less time consuming.

Using obtained during the experiments dimensions and average velocity of miniflow, the whole spectrum of hydraulic parameters of analyzed protective coatings with the final roughness coefficient of the corresponding coatings " $n$ " was determined.

As an example, Summary table 1 shows the studies results on the hydrophobicity of coatings obtained as experimental data, designed geometrical parameters of miniflow and hydraulic characteristics of two work surfaces (photo 2988 and 3185 in Fig. 5).

The calculation algorithm of hydraulic exponents is to determine: filling $(h / d)$ and wetted perimeter (arc length $A F C$ ) of miniflow; average hydraulic radius $R$; velocity of miniflow $V$, as the quotient of the path $P$ division, passed by the miniflow head in time $T$, measured by the stopwatch; Chezy's velocity factor $C$, which depends on the hydraulic radius $r$, velocity $V$ and slope $i\left(C=V /(R i)^{0,5}\right.$; relative roughness coefficient $n$ using Manning's formula:

$$
C=\frac{1}{n} \cdot R^{1 / 6}
$$


According to the presented calculation method the roughness coefficient " $\mathrm{n}$ " by Manning for polypropylene based on the results of experiments was $n=0.0132$ at relative hydrophobicity ratio $K_{\text {отн. }}=1.0655$. For other protective coatings the roughness coefficient ranged from 0.009 to 0.0098 and relative hydrophobicity ratios within 1.075-1.098, respectively (for Smart Surface coating 1.098). Thus, the correlation between relative hydrophobicity ratios and relative roughness coefficients was found: the higher the hydrophobicity, the lower the material roughness.

Table 1. The calculation results of geometrical parameters and hydraulic characteristics of miniflow in the tray of $d=130 \mathrm{~mm}$ in diameter with a slope $i=0,11$

\begin{tabular}{|c|c|c|c|c|c|c|}
\hline $\begin{array}{c}\text { Photo } \\
\text { number }\end{array}$ & $\begin{array}{c}A B C O A \\
\text { upper } \\
\text { lens area } \\
S_{u p}, \mathrm{~mm}^{2}\end{array}$ & $\begin{array}{l}\text { Wetted } \\
\text { perimeter } \\
A F C, m m\end{array}$ & $\begin{array}{c}\text { Wetted } \\
\text { surface } \\
A^{\wedge} C^{`} C^{\prime} \\
S_{w e t}, \mathrm{~mm}^{2}\end{array}$ & $\begin{array}{c}\text { Relative } \\
\text { hydrophobi- } \\
\text { city } \\
\text { indicator } \\
\boldsymbol{K}_{r e l} \\
\end{array}$ & $\begin{array}{l}\text { Contact } \\
\text { angle } \alpha^{0}\end{array}$ & $\begin{array}{c}\text { Design } \\
\text { value } \\
L_{p a c u,}, \\
m m\end{array}$ \\
\hline 2988 & 25.62 & 14.56 & 218.539 & 1.065 & $36^{0} 12^{\prime}$ & 15.09 \\
\hline 3185 & 25.33 & 11.89 & 214.187 & 1.075 & $45^{0} 18^{\prime}$ & 20.07 \\
\hline $\begin{array}{c}\text { Photo } \\
\text { number }\end{array}$ & $\begin{array}{c}\text { Average } \\
\text { hydraulic } \\
\text { radius } R, \\
m m\end{array}$ & $\begin{array}{c}\text { Miniflow } \\
\text { path } \\
P, m m\end{array}$ & $\begin{array}{c}\text { Travel time } \\
T, s\end{array}$ & $\begin{array}{c}\text { Average } \\
\text { velocity of } \\
\text { miniflow } \\
V, \mathrm{~mm} / \mathrm{s}\end{array}$ & $\begin{array}{l}\text { Chezy's }^{\prime} \\
\text { velocity } \\
\text { factor C }\end{array}$ & $\begin{array}{c}\text { Relative } \\
\text { roughness } \\
\text { coefficient } \\
n\end{array}$ \\
\hline 2988 & 0.38 & 90 & 5 & 18 & 64.52 & 0.0132 \\
\hline 3185 & 0.34 & 83 & 5 & 16.6 & 88.09 & 0.0096 \\
\hline
\end{tabular}

\section{Conclusions}

Static studies of water repellent studies (hydrophobic) properties of the protective coatings used in pipelines have shown that most of them have a low degree of hydrophobicity (contact angles are within the range of $36-60^{\circ}$ ).

Dynamic studies of the miniflow movement on the Smart Surface coating have shown that it has well-defined hydrophobic properties; this circumstance favors the Smart Surface coating in comparison with alternative work materials of free-flow pipeline walls, because it contributes to the reduction of contact area at the liquid flow and leads to lower friction losses during the flow movement.

Studies of the miniflow liquid movement on the inclined trough have shown that by determining the relative hydrophobic ratio of protective coatings the hydraulic flow exponents can be evaluated (recalculated), in particular, the relative roughness coefficient of the analyzed material; as a result it has been proposed to use the small-scale installations for hydrophobicity study of different materials instead of bulky hydraulic stands for the hydraulic characteristics determination.

\section{References}

1. A. Kuliczkowski, Rury kanalizacyjne Tom II. Projektowanie konstrukcji (Wyd. Politechniki Świętokrzyski, Kielce, 2004)

2. M. Rameil, Handbook of pipe bursting practice (Vulkan-Verlag GmbH, 2007)

3. A. Zwierzchowska, Technologie bezwykopowej budowy sieci gazowych, wodociagowych i kanalizacyjnych (Skrypt Politechniki Świętokrzyskie, Kielce, 2012)

4. S.V. Khramenkov, O.G. Primin, V.A. Orlov, Reconstruction of pipeline systems (DIA, 2008)

5. D. Oner, T.J. McCarthy, Langmuir 16(20), 7777-7782 (2000) 
6. N. Le Grand, A. Daerr, L. Limat, J. Fluid Mech 541, 293-315 (2005)

7. V.A. Orlov, Pipelines protecting coatings (DIA, 2009)

8. A. Kibar, H. Karabay, K. Suleyman Yigit, Ikrime O. Ucar, H. Yıldırım Erbil, Exp. Fluids 49, 1135-1145 (2010)

9. C. Lee, C.-J. Kim, Langmuir 27(7), 4243-4248 (2011)

10. J. J. Bikerman, J. Colloid Sci. 5, 349-359 (1950)

11. A.V. Belyaev, O.I. Vinogradova, Soft Matter 6, 4563-4570 (2010)

12. A. Gajewski, Int. J. Heat Mass Transf. 48(23-24), 4829-4834 (2005)

13. T. Baldacchini, J.E. Carey, M. Zhou, E. Mazur, Langmuir 22(11), 4917-4919 (2006)

14. Reyssat, D. Quere, J. Phys. Chem. B. 113(12), 3906-3909 (2009)

15. L. Gao, T.J. McCarthly, Langmuir 22(14), 6234-6237 (2006)

16. H.Y. Kim, H.J. Lee, B.-H. Kang, J. Colloid Interface Sci. 247, 372-380 (2002)

17. Y. Wang, B. Bhushan, A. Maali, J. Vac. Sci. Technol. A. 27, 754-760 (2009)

18. B. Dussan, Annu. Rev. Fluid Mech. 11, 371-400 (1979)

19. M. Sakai, J.H. Song, N. Yoshida, S. Suzuki, Y. Kameshima, A. Nakajima, Langmuir 22, 4906-4909 (2006)

20. M. Sakai, J.-H. Song, N. Yoshida, S. Suzuki, Y. Kameshima, A. Nakajima, Surface Science 600(16), 204-208 (2006)

21. F. Brochard, P.G. de Gennes, Langmuir 15, 3024-3028 (1992)

22. P.G. de Gennes, Rev. Mod. Phys 57(3), 827-863 (1985)

23. R. Golestanian, E. Raphael, Phys. Rev. E 67, 031603 (2003) 